\title{
Descarga de HSV-1, HSV-2, CMV y EBV en la saliva de receptores de trasplante de precursores hematopoyéticos de la Fundación HOMI - Hospital de la Misericordia, Bogotá, D. C.
}

\author{
Sonia P. Bohórquez¹, Juliana Díaz¹, Claudia M. Rincón¹, Marcela Estupiñán², Mauricio Chaparro², \\ Ana María Low-Calle ${ }^{3}$, Jaime E. Castellanos ${ }^{1,3}$ \\ 1 Grupo de Investigación en Patogénesis Infecciosa, Facultad de Odontología, Universidad Nacional de \\ Colombia, Bogotá, D.C., Colombia \\ 2 Unidad de Trasplante, Fundación HOMI - Hospital de la Misericordia, Bogotá, D.C., Colombia \\ 3 Grupo de Virología, Universidad El Bosque, Bogotá, D.C., Colombia
}

Introducción. El trasplante de precursores hematopoyéticos es una alternativa en el tratamiento de diversas condiciones en la población pediátrica. La intensidad del acondicionamiento para el trasplante predispone al desarrollo de complicaciones en los receptores. Las infecciones por el virus herpes simple 1 (HSV-1), el virus herpes simple 2 (HSV-2), el citomegalovirus (CMV) humano y el virus de Epstein-Barr (EBV) son una causa importante de morbimortalidad en estos pacientes. La reactivación de infecciones latentes puede producir descargas virales asintomáticas detectables en la saliva, lo cual ayuda a determinar el comportamiento de dichas infecciones en pacientes con trasplante y a establecer el diagnóstico temprano de la reactivación.

Objetivo. Evaluar el comportamiento de la descarga viral de HSV-1, HSV-2, CMV y EBV en la saliva de pacientes hospitalizados en la Unidad de Trasplante de la Fundación HOMI - Hospital de la Misericordia, entre enero y noviembre de 2012.

Materiales y métodos. Se evaluaron muestras de saliva de 17 receptores de trasplante. La presencia de ADN de HSV-1, HSV-2, CMV y EBV en las muestras de saliva se detectó mediante reacción en cadena de la polimerasa convencional.

Resultados. Se detectó el ADN del HSV-2 en la saliva de cuatro pacientes, del CMV en la de cuatro y del EBV en la de nueve, lo cual se asoció con leucopenia. Cuatro de los 17 pacientes presentaron cargas simultáneas de CMV y EBV. No se detectó el ADN del HSV-1.

Conclusiones: Se demostró una descarga asintomática de HSV-2, CMV y EBV asociada a leucopenia en la saliva de los pacientes.

Palabras clave: Herpesviridae, simplexvirus, herpes simple, citomegalovirus, herpesvirus humano 4, trasplante de médula ósea, trasplante de células madre hematopoyéticas.

doi: http://dx.doi.org/10.7705/biomedica.v36i0.2985

\begin{abstract}
Shedding of HSV-1, HSV-2, CMV, and EBV in the saliva of hematopoietic stem cell transplant recipients at Fundación HOMI - Hospital de la Misericordia, Bogotá, D.C.
\end{abstract}

Introduction: Hematopoietic stem cell transplantation in pediatric patients is an alternative treatment for different diseases. The conditioning regimen for transplant predisposes recipients to the development of infections. Viral infections by herpes simplex virus 1 (HSV-1), herpes simplex virus 2 (HSV-2), human cytomegalovirus (CMV), and Epstein-Barr virus (EBV), are the most common, and the leading cause of morbidity and mortality among these patients. These viruses lie dormant in various cell types and the reactivation of latent infections may lead to asymptomatic viral shedding in saliva. The detection of these viruses in secretions may contribute to understand the behavioral dynamics of these viral infections in transplanted patients, and to the early diagnosis of reactivation. Objective: To assess HSV-1, HSV-2, CMV and EBV viral shedding in the saliva of patients admitted for hematopoietic stem cell transplantation at Fundación HOMI - Hospital de la Misericordia between January and November of 2012.

\footnotetext{
Contribución de los autores:

Sonia P. Bohórquez: elaboración del proyecto, revisión de la literatura, recolección de las muestras, análisis de los resultados y escritura del manuscrito

Juliana Díaz y Claudia M. Rincón: recolección y procesamiento de las muestras, análisis de los resultados y escritura del manuscrito Marcela Estupiñán y Mauricio Chaparro: elaboración del proyecto y análisis de resultados

Ana María Low-Calle: procesamiento de las muestras

Jaime E. Castellanos: elaboración del proyecto, procesamiento de las muestras, análisis de los resultados y escritura del manuscrito
} 
Materials and methods: We evaluated stimulated saliva samples of 17 hematopoietic stem cell transplantation recipients weekly. We performed DNA extraction from saliva, and we evaluated the presence of DNA for HSV-1, HSV-2, CMV, and EBV by PCR.

Results: While we detected HSV-2 and CMV DNA in the saliva of four patients, EBV DNA was detected in nine patients with leukopenia. In contrast, we did not detect HSV-1 DNA in saliva. Additionally, four out of the 17 patients showed a simultaneous shedding of CMV and EBV.

Conclusions: By conventional PCR, we demonstrated asymptomatic HSV-2, CMV, and EBV viral shedding in saliva, associated with leukopenia.

Key words: Herpesviridae, simplexvirus, herpes simplex, cytomegalovirus, herpesvirus 4, bone marrow transplantation, hematopoietic stem cell transplantation.

doi: http://dx.doi.org/10.7705/biomedica.v36i0.2985

Los virus herpes son los principales agentes patógenos en la cavidad oral de los seres humanos $(1,2)$. La familia Herpesviridae se agrupa en tres subfamilias: la alfa, que incluye el virus herpes simple 1 (HSV-1), el virus herpes simple 2 (HSV-2) y el virus varicela zóster (VZV); la beta, que incluye el citomegalovirus (CMV) humano, el virus herpes humano 6 (HSV-6) y 7 (HSV-7), y la gamma, que incluye el virus de Epstein-Barr (EBV) y el HSV-8 (3).

Además de producir infecciones líticas, una de las principales características de los virus herpes es su capacidad de latencia debida al equilibrio entre el virus y el sistema inmunológico del huésped, con su consecuente persistencia asintomática. El ADN latente puede desencadenar la reactivación y el ensamblaje de los virus y dar lugar a síntomas o no, aunque facilita la transmisión en huéspedes seronegativos (4-7).

Dicha transmisión ocurre principalmente por contacto directo o próximo con individuos sintomáticos, pero se ha demostrado la presencia temporal de partículas virales en las secreciones de individuos infectados que no manifiestan signos ni síntomas; a esto se le ha denominado descarga o eliminación (shedding) viral asintomática, la cual puede detectarse en saliva, orina, leche materna, lágrimas y semen. Las descargas de HSV-1, HSV-2, CMV y EBV están bien documentadas en individuos inmunocompetentes, sometidos a tratamientos odontológicos e inmunosuprimidos (8-15).

El acondicionamiento previo al trasplante de precursores hematopoyéticos produce una considerable inmunosupresión y, consecuentemente,

\section{Correspondencia:}

Sonia del Pilar Bohórquez, Facultad de Odontología,

Universidad Nacional de Colombia, Carrera $30 \mathrm{~N}^{\circ} 45-03$,

edificio 210, oficina 301, Bogotá, D.C., Colombia

Teléfono: (571) 316 5000, extensión 16017

spbohorqueza@unal.edu.co

Recibido: 21/07/15; aceptado: 19/05/16 eleva la morbimortalidad después del trasplante, principalmente en los receptores de trasplantes alogénicos. La recuperación del sistema inmunológico después de un trasplante de precursores hematopoyéticos es gradual, con una fase inicial de reducción inmunológica inmediatamente después del trasplante, hasta la recuperación de los neutrófilos. La segunda fase va desde el momento del injerto en la médula ósea hasta el tercer o cuarto mes, y el efecto más importante se produce en la inmunidad mediada por células (16).

Hasta hace algunos años, las infecciones y reactivaciones por HSV-1 y HSV-2 frecuentemente aumentaban la morbimortalidad en los pacientes con trasplante, y el riesgo de complicaciones se incrementaba debido a la mucositis gastrointestinal, por lo cual, desde la década de los 80 , se administra a todos los pacientes una profilaxis antiviral con aciclovir (11).

La infección y reactivación por CMV continúa siendo uno de los problemas más importantes para los receptores de trasplantes. Esto ha impuesto la necesidad de desarrollar protocolos para el diagnóstico temprano mediante reacción en cadena de la polimerasa (PCR) o la detección de la antigenemia, y para la profilaxis y el tratamiento anticipado con ganciclovir (16).

Se ha detectado la descarga asintomática de CMV en la saliva de receptores de trasplante de precursores hematopoyéticos. Correia-Silva, et al., evaluaron la descarga oral de CMV en receptores de trasplante alogénico y concluyeron que la detección del virus en la saliva puede contribuir a un diagnóstico temprano de su reactivación o infección en este grupo de pacientes (17).

EI EBV es uno de los virus más comunes en los seres humanos; la mayoría de las infecciones es asintomática, pero debe destacarse su asociación con neoplasias malignas, como el linfoma de Burkitt y el carcinoma nasofaríngeo, entre otras. 
En los receptores de trasplante se ha asociado con el síndrome linfoproliferativo postrasplante $(18,19)$.

Debido a la inmunosupresión causada por el acondicionamiento previo al trasplante, el equilibrio entre el sistema inmunológico y los virus herpes en latencia se puede alterar, propiciando su reactivación. Igualmente, si el paciente es seronegativo y adquiere la infección durante el periodo de inmunosupresión (principalmente el $\mathrm{CMV}$ ), pueden presentarse complicaciones que lleven al fracaso del trasplante. La detección de estas reactivaciones e infecciones antes del inicio de los síntomas es importante en la prevención y el control de tales complicaciones.

Dado que estos cuatro virus herpes pueden detectarse en la saliva, en este estudio se propuso evaluar la descarga de HSV-1, HSV-2, CMV y EBV en la saliva de receptores de trasplante de precursores hematopoyéticos de la Fundación HOMI - Hospital de la Misericordia.

\section{Materiales y métodos}

Se llevó a cabo un estudio observacional de tipo longitudinal para evaluar la descarga de HSV-1, HSV-2, CMV y EBV en la saliva de los pacientes que ingresaron a la Unidad de Trasplante de Precursores Hematopoyéticos en la Fundación HOMI - Hospital de la Misericordia, en el período comprendido entre enero y noviembre de 2012. Se excluyeron los pacientes cuyos padres 0 acudientes no aceptaron participar y aquellos de quienes no se pudo obtener una muestra adecuada de saliva después de dos intentos.

Se obtuvo información de la historia clínica sobre el recuento de leucocitos en el momento de la toma de muestras de saliva, la detección de anticuerpos específicos para alguno de los virus evaluados y la antigenemia o el resultado de la PCR para detectar la reactivación de CMV. El valor de referencia normal de leucocitos en sangre en esta institución fluctúa entre 4.500 y 13.500 células $/ \mu$ l.

\section{Recolección de muestras}

Se recolectaron muestras semanales de saliva de cada paciente a partir del momento de la hospitalización en la unidad de trasplantes y durante la permanencia en esta, hasta tres meses máximo. Se estimuló la secreción de saliva solicitando al paciente que masticara un trozo de cera para base de uso odontológico y luego se recolectó la saliva en un tubo estéril de $50 \mathrm{ml}$ que contenía $500 \mu \mathrm{l}$ de medio de transporte DMEM (Dubelcco's Modified Eagle Medium), $100 \mathrm{UI} / \mathrm{ml}$ de penicilina y $10 \mu \mathrm{g} /$ $\mathrm{ml}$ de estreptomicina. Las muestras se refrigeraron a $4{ }^{\circ} \mathrm{C}$ y se transportaron al laboratorio para su procesamiento.

\section{Procesamiento de muestras}

Una vez en el laboratorio, bajo condiciones de asepsia y en cabina de flujo laminar, las muestras se diluyeron en proporción de uno a uno en PBS, y se centrifugaron a $5.000 \mathrm{rpm}$ o 3.186 RCF durante 10 minutos a $4^{\circ} \mathrm{C}$. El sobrenadante se transfirió a un tubo de microcentrífuga de $1,5 \mathrm{ml}$ y se almacenó a $-80{ }^{\circ} \mathrm{C}$ hasta su uso.

\section{Extracción de ADN}

La extracción de ADN se hizo en $50 \mu$ de cada muestra. Se agregaron $150 \mu \mathrm{l}$ de la siguiente solución: resina Chelex 100 al $20 \%$ en 10 mM de Tris- $\mathrm{HCl}(\mathrm{pH} 8,0), 0,1 \mathrm{mM}$ de EDTA, y azida de sodio al $0,1 \%$. Esta mezcla se agitó en un agitador de tipo vórtex durante 10 segundos y se incubó a $56{ }^{\circ} \mathrm{C}$ durante 20 minutos. Después de otros 10 segundos de agitación en el agitador vórtex, la mezcla se incubó a $100{ }^{\circ} \mathrm{C}$ durante 10 minutos $y$, posteriormente, se dejó enfriar a temperatura ambiente. Tras observar un completo asentamiento de la resina, se recolectó el sobrenadante en un tubo nuevo y se almacenó a $-20^{\circ} \mathrm{C}$ hasta su uso (20).

En el cuadro 1 se presentan las condiciones de amplificación mediante PCR del ADN de HSV-1, HSV-2, CMV y EBV. Se decidió llevar a cabo la amplificación mediante PCR por separado para HSV-1 y HSV-2 primero, y después para CMV y EBV.

Para detectar el ADN de HSV-1 y HSV-2 mediante una PCR anidada, se siguió el protocolo descrito por Sun, et al. (21), usando un par de iniciadores externos (TO1 y TO2) y haciendo una nueva amplificación con tres iniciadores (TIA, TIB1 y TIB2), lo cual da como resultado un amplicón de 129 pb si está presente el HSV-1 (TIA + TIB1) y un amplicón de 163 pb si está presente el HSV-2 (TIA + TIB2). Como control positivo se utilizó el sobrenadante de células Vero infectadas con HSV-1 y HSV-2.

Las secuencias de los iniciadores para la detección del ADN de CMV amplifican un fragmento de 242 $\mathrm{pb}$, el cual codifica para la proteína estructural UL56. Como control positivo se usaron células mononucleares de sangre periférica de un paciente con infección confirmada por CMV (22). 
Cuadro 1. Especificaciones de la reacción en cadena de la polimerasa (PCR) para cada virus

\begin{tabular}{|c|c|c|c|c|}
\hline & HSV-1 & HSV-2 & CMV & EBV \\
\hline & PCR anidada & PCR anidada & PCR convencional & PCR convencional \\
\hline Gen blanco & ADN polimerasa viral & ADN polimerasa viral & UL56 & ADN polimerasa viral \\
\hline Iniciadores & \multicolumn{2}{|c|}{$\begin{array}{l}\text { Primera ronda, } \\
\text { iniciador sentido TO1 (5'-GGC CAG } \\
\text { CAG ATC CGC GTC TT-3'), } \\
\text { Iniciador antisentido TO2 (5'-GCT } \\
\text { GGG GTA CAG GCT GGC AA -3') } \\
\text { Segunda ronda, iniciador sentido TIA } \\
\text { (5'-CTG CCG GAC ACC CAG GGG CG-3') } \\
\text { Iniciador antisentido TIB1 (5'-CCC GCC } \\
\text { CTC CTC GCG TTC GT-3') } \\
\text { Iniciador antisentido TIB2 (5'-CGA CCT } \\
\text { CCT CGC GCT CGT CC-3') }\end{array}$} & $\begin{array}{l}\text { Iniciador sentido (5'-ACG TGT } \\
\text { TAC TGG CGG AGTCG-3') } \\
\text { 0,5 mM, iniciador antisentido (5'- } \\
\text { TTGAGTGTGGCCAGACTGAG -3') }\end{array}$ & $\begin{array}{l}\text { (ACTCGTGCACGTGCTT } \\
\text { CTTTAC) }\end{array}$ \\
\hline $\begin{array}{l}\text { Protocolo de } \\
\text { amplificación }\end{array}$ & \multicolumn{2}{|c|}{$\begin{array}{l}\text { Temperatura inicial de } 95^{\circ} \mathrm{C} \text { durante } \\
\text { tres minutos; } 25 \text { ciclos a } 95^{\circ} \mathrm{C} \text { durante } \\
30 \text { segundos, a } 65^{\circ} \mathrm{C} \text { durante } 30 \text { segundos, } \\
\text { a } 72^{\circ} \mathrm{C} \text { durante } 45 \text { segundos; extensión } \\
\text { final a } 72{ }^{\circ} \mathrm{C} \text { durante } 10 \text { minutos y } \\
\text { enfriamiento a } 4{ }^{\circ} \mathrm{C}\end{array}$} & $\begin{array}{l}\text { Temperatura inicial de } 95^{\circ} \mathrm{C} \\
\text { durante tres minutos; } 45 \text { ciclos } \\
\text { a } 95^{\circ} \mathrm{C} \text { durante } 30 \text { segundos, } \\
\text { a } 54^{\circ} \mathrm{C} \text { durante } 30 \text { segundos, } \\
\text { a } 72^{\circ} \mathrm{C} \text { durante } 30 \text { segundos; } \\
\text { extensión final a } 72{ }^{\circ} \mathrm{C} \text { durante } \\
7 \text { minutos y enfriamiento a } 4^{\circ} \mathrm{C}\end{array}$ & $\begin{array}{l}\text { Temperatura inicial de } \\
94^{\circ} \mathrm{C} \text { durante } 2 \text { minutos } \\
39 \text { ciclos de } 30 \text { segundos } \\
\text { a } 94^{\circ} \mathrm{C}, 45 \text { segundos a } \\
60{ }^{\circ} \mathrm{C} \text { y } 45 \text { segundos a } \\
72^{\circ} \mathrm{C} \text {; para finalizar, } 10 \\
\text { minutos a } 72{ }^{\circ} \mathrm{C}\end{array}$ \\
\hline $\begin{array}{l}\text { Control } \\
\text { positivo }\end{array}$ & $\begin{array}{l}\text { Sobrenadantes de } \\
\text { células Vero infectadas } \\
\text { con HSV-1 }\end{array}$ & $\begin{array}{l}\text { Sobrenadantes } \\
\text { de células Vero } \\
\text { infectadas con HSV-2 }\end{array}$ & $\begin{array}{l}\text { Células mononucleares de sangre } \\
\text { periférica de un paciente con } \\
\text { infección confirmada por CMV }\end{array}$ & Células TK6 \\
\hline Referencia & 21 & 21 & 22 & 23 \\
\hline
\end{tabular}

Para la detección del EBV se empleó el protocolo reportado por Sahin, et al., con el cual se amplifica un producto de $176 \mathrm{pb}$ (23). El control positivo consistió en ADN de células TK6, las cuales, como se sabe, son positivas para este virus.

En todos los casos, los productos de la reacción de cada muestra se separaron en una electroforesis de agarosa y se tiñeron con bromuro de etidio para su visualización y fotografía.

\section{Consideraciones éticas}

Este proyecto fue aprobado por el Comité de Ética de la Facultad de Odontología de la Universidad Nacional de Colombia y por la Gerencia Científica de la Fundación HOMI - Hospital de la Misericordia.

\section{Resultados}

En el periodo comprendido entre enero y noviembre de 2012, se hospitalizaron 18 pacientes en la Unidad de Trasplante de Precursores Hematopoyéticos de la Fundación HOMI - Hospital de la Misericordia; uno de ellos se excluyó del estudio porque en dos ocasiones las muestras fueron insuficientes para el procesamiento. En total, se recolectaron y procesaron 105 muestras de saliva de los 17 pacientes incluidos en el estudio: entre 3 y 13 muestras por paciente, dependiendo del periodo de hospitalización.
Nueve de los pacientes eran de sexo femenino (52,9 \%); la edad fluctuó entre los 3 y los 17 años (mediana de 9 años y promedio de 10,1 años), y la mayoría estaba en el rango de 7 a 15 años (cuadro 2).

En cuanto a los diagnósticos en el momento de la hospitalización, la distribución fue la siguiente: siete $(41,1 \%)$ pacientes tenían leucemia linfoide aguda; seis (35,3\%), leucemia mieloide aguda; dos (12\%), linfoma de Hodgkin; uno (5,8\%), anemia aplásica idiopática, y otro (5,8\%), neuroblastoma.

De los 17 pacientes, nueve (52,9\%) recibieron trasplante alogénico de cordón umbilical, cinco $(29,4 \%)$, trasplante alogénico de donante idéntico emparentado, y tres (17,7\%), trasplante autólogo (cuadro 2).

Mediante PCR se estableció que había decsarga viral en las muestras de diez $(58,9 \%)$ de los 17 pacientes evaluados. En cuatro $(23,5 \%)$ de ellos se detectó descarga de HSV-2; en cuatro (23,5\%), de CMV, y en nueve (52,9\%), de EBV. En ninguna de las muestras se detectó el HSV-1 (cuadro 3). En la figura 1 se muestran los hallazgos en la electroforesis en gel de agarosa.

Los cuatro pacientes con descarga positiva para CMV también presentaban EBV; otros tres presentaban EBV y HSV-2 simultáneamente, 
y el paciente 5 presentó los tres virus, pero no de forma simultánea. Todas las descargas eran asintomáticas; en el momento de la toma de las muestras, ningún paciente presentaba lesiones en la mucosa oral similares a las causadas por el virus del herpes.

Como se muestra en el cuadro 3, en 51 (48,6 \%) de las 105 muestras de saliva se detectó, al menos, uno de los virus evaluados: 29 (27,6 \%) fueron positivas para EBV, 12 (11,4\%), para CMV, y 10 $(9,5 \%)$, para HSV-2.

En la muestra número 12, el recuento leucocitario de la paciente 2 fue de 2.700/ $\mu$; se encontraron hemoblastos leucémicos en sangre periférica y se diagnosticó una recaída de la leucemia. Al paciente 5 se le diagnosticó el síndrome linfoproliferativo postrasplante después de la semana 12.

En el cuadro 3 se muestra el conteo de leucocitos, además de los resultados de cada muestra de saliva positiva en la respectiva semana. En algunos casos se registraron datos sobre el recuento leucocitario porque no hubo información disponible en el día de la toma de la muestra.

\section{Discusión}

Las descargas virales asintomáticas son un importante medio de transmisión del virus del herpes, y la saliva es una de las secreciones que más se ha estudiado, principalmente en la detección de HSV-1; se ha comprobado la descarga de HSV-2, CMV y EBV $(8,12,14)$. Igualmente, se ha demostrado que estas descargas tienen un comportamiento dinámico y variable, lo cual significa que no siguen un patrón uniforme y que pueden presentarse en distintos momentos del día. En individuos positivos para HIV, se ha observado esta variabilidad en la descarga de HSV-1 y HSV-2 en hisopados de la cavidad oral a distintas horas y durante periodos de hasta 30 días (10).

En el cuadro 3 se presenta este comportamiento en los pacientes con descargas virales. En el caso del HSV-2, solo el paciente 2 presentó más de una

Cuadro 2. Distribución de los pacientes por edad, sexo, diagnóstico, tipo de trasplante, serología y estatus para CMV

\begin{tabular}{|c|c|c|c|c|c|c|}
\hline Paciente & Edad & Sexo & Diagnóstico & $\begin{array}{l}\text { Tipo de } \\
\text { trasplante }\end{array}$ & Serología & CMV \\
\hline 1 & 12 & M & Linfoma de Hodgkin & Autólogo & ND & PCR negativa al egreso \\
\hline 2 & 16 & $\mathrm{~F}$ & LMA & TACU & $\begin{array}{l}\text { HSV-1: } \lg G(+), \lg M(-) \\
\text { HSV-2: } \operatorname{lgG}(-), \operatorname{lgM}(-) \\
\text { EBV: } \operatorname{lgG}(-), \lg M(-)\end{array}$ & $\begin{array}{c}\text { CMV IgG (-) } \\
\text { Donante negativo }\end{array}$ \\
\hline 3 & 6 & M & LLA & TACU & ND & $\begin{array}{c}\text { Donante } \lg G(+) \\
\text { Antigenemia (+) en la semana } 7\end{array}$ \\
\hline 4 & 17 & M & LLA & TADI & ND & ND \\
\hline 5 & 16 & M & LLA & TACU & ND & $\begin{array}{c}\text { Donante IgG (+); PCR positiva } \\
\text { en la semana } 12\end{array}$ \\
\hline 6 & 9 & $\mathrm{~F}$ & LLA & TACU & ND & Antigenemia (+) en la semana 7 \\
\hline 7 & 4 & $\mathrm{~F}$ & LLA & TACU & $\begin{array}{l}\text { HSV-1: IgG (-), IgM (-) } \\
\text { HSV-2: IgG (-), IgM (-) }\end{array}$ & Antigenemia (+) en la semana 7 \\
\hline 8 & 10 & $\mathrm{~F}$ & $\begin{array}{l}\text { Anemia aplásica } \\
\text { adquirida }\end{array}$ & TADI & ND & ND \\
\hline 9 & 9 & $\mathrm{~F}$ & LMA & TACU & ND & ND \\
\hline 10 & 5 & M & $\begin{array}{l}\text { Neuroblastoma de } \\
\text { alto riesgo }\end{array}$ & Autólogo & ND & ND \\
\hline 11 & 16 & M & $\begin{array}{l}\text { Linfoma de Hodgkin } \\
\text { en recaída }\end{array}$ & Autólogo & ND & ND \\
\hline 12 & 7 & $\mathrm{~F}$ & LMA & TADI & $\begin{array}{l}\text { HSV-1: } \lg G(+), \lg M(-) \\
\text { HSV-2: } \lg G(-), \lg M(-) \\
\text { EBV: } \lg G(+), \lg M(-)\end{array}$ & $\lg G(+), \lg M(-)$ \\
\hline 13 & 7 & $\mathrm{~F}$ & LLA & TACU & & $\begin{array}{c}\lg G(+), \operatorname{lgM}(+) \\
\text { PCR negativa al ingreso } \\
\text { y en las semanas } 3,4 \text { y } 5\end{array}$ \\
\hline 14 & 13 & $\mathrm{~F}$ & LMA & TADI & ND & ND \\
\hline 15 & 8 & M & LLA & TACU & ND & ND \\
\hline 16 & 14 & M & LMA & TACU & ND & ND \\
\hline 17 & 3 & $\mathrm{~F}$ & LMA & TADI & ND & ND \\
\hline
\end{tabular}

LMA: leucemia mieloide aguda; LLA: leucemia linfoide aguda; TACU: trasplante alogénico de cordón umbilical; TADI: trasplante alogénico de donante idéntico; ND: sin datos; PCR: reacción en cadena de la polimerasa 
Cuadro 3. Pacientes con descargas virales positivas por semana y recuento leucocitario por $\mu \mathrm{l}$ en el día de toma de la muestra

\begin{tabular}{|c|c|c|c|c|c|c|c|c|c|c|c|c|}
\hline \multirow[t]{2}{*}{ Paciente } & \multicolumn{12}{|c|}{ Semana } \\
\hline & 1 & 2 & 3 & 4 & 5 & 6 & 7 & 8 & 9 & 10 & 11 & 12 \\
\hline 1 & $\begin{array}{l}\text { EBV } \\
4200\end{array}$ & $\begin{array}{c}\text { EBV } \\
3980\end{array}$ & $\begin{array}{c}\text { EBV } \\
40\end{array}$ & $\begin{array}{c}\text { EBV } \\
300\end{array}$ & $\begin{array}{c}\text { EBV } \\
1000\end{array}$ & & & & & & & \\
\hline 2 & & & & $\begin{array}{c}\text { HSV-2 } \\
0\end{array}$ & & $\begin{array}{c}\text { HSV-2 } \\
340\end{array}$ & $\begin{array}{c}\text { HSV-2 } \\
\text { EBV } \\
720\end{array}$ & $\begin{array}{c}\text { HSV-2 } \\
\text { EBV } \\
1080\end{array}$ & $\begin{array}{c}\text { HSV-2 } \\
\text { EBV } \\
320\end{array}$ & $\begin{array}{c}\text { HSV-2 } \\
73\end{array}$ & $\begin{array}{c}\text { HSV-2 } \\
\text { EBV } \\
2700\end{array}$ & \\
\hline 3 & $\begin{array}{l}\text { EBV } \\
2500\end{array}$ & $\begin{array}{l}\text { CMV } \\
2200\end{array}$ & $\begin{array}{c}\mathrm{CMV} \\
0\end{array}$ & & $\begin{array}{l}\text { EBV } \\
250\end{array}$ & $\begin{array}{c}\text { EBV } \\
810\end{array}$ & & & & & & \\
\hline 5 & $\begin{array}{l}\text { CMV } \\
\text { EBV } \\
3400\end{array}$ & $\begin{array}{c}\text { HSV-2 } \\
\text { EBV } \\
3670\end{array}$ & & & & & & $\begin{array}{c}\text { EBV } \\
40\end{array}$ & $\begin{array}{c}\text { EBV } \\
70\end{array}$ & $\begin{array}{c}\text { EBV } \\
60\end{array}$ & & $\begin{array}{c}\text { EBV } \\
10\end{array}$ \\
\hline 6 & $\begin{array}{l}\text { CMV } \\
\text { EBV } \\
4830\end{array}$ & & $\begin{array}{c}\text { CMV } \\
20\end{array}$ & $\begin{array}{c}\text { CMV } \\
270\end{array}$ & CMV & $\begin{array}{c}\text { CMV } \\
\text { EBV } \\
290\end{array}$ & $\begin{array}{c}\text { CMV } \\
\text { EBV } \\
110\end{array}$ & $\begin{array}{l}\text { CMV } \\
\text { EBV }\end{array}$ & & & & \\
\hline 7 & & & & $\begin{array}{c}\text { CMV } \\
80\end{array}$ & & & $\begin{array}{l}\text { CMV } \\
\text { EBV } \\
1690\end{array}$ & & & & & \\
\hline 8 & & & $\begin{array}{c}\text { EBV } \\
110\end{array}$ & $\begin{array}{c}\text { EBV } \\
3000\end{array}$ & & & & & & & & \\
\hline 11 & $\begin{array}{c}\text { HSV-2 } \\
\text { EBV } \\
6030\end{array}$ & $\begin{array}{c}\text { EBV } \\
3694\end{array}$ & & $\begin{array}{l}\text { EBV } \\
7680\end{array}$ & & & & & & & & \\
\hline 13 & & $\begin{array}{c}\text { HSV-2 } \\
40\end{array}$ & & & & & & & & & & \\
\hline 17 & & & $\begin{array}{c}\text { EBV } \\
330\end{array}$ & & & & & & & & & \\
\hline
\end{tabular}
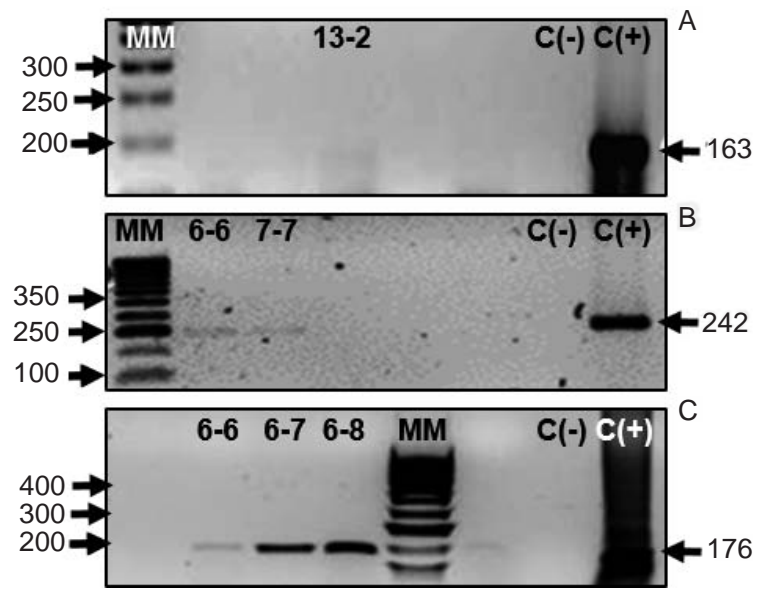

Figura 1. A. Electroforesis en gel de agarosa del producto de amplificación de 163 pb para la ADN polimerasa del HSV-2. Paciente 13, muestra 2 positiva. B. Electroforesis en gel de agarosa del producto de amplificación de 242 pb para el gen UL56 del CMV. Paciente 6, muestras 6 y 7 positivas. C. Electroforesis en gel de agarosa del producto de amplificación de 176 pb para el gen de la ADN polimerasa del EBV. Paciente 6 , muestras 6,7 y 8 positivas.

muestra positiva, en la semana 4 y a partir de la semana 6 en todas las muestras; en los otros tres pacientes, sola una muestra fue positiva. En cuanto a las descargas del virus de Epstein-Barr, los nueve positivos presentaron más de una descarga, excepto los pacientes 7 y 17, en quienes se detectó en una sola oportunidad. Se observó un comportamiento semejante para las descargas de CMV, y el paciente 5 tuvo una muestra positiva.

Las descargas de HSV-1 en saliva se han estudiado con mucha mayor frecuencia que las de HSV-2; usualmente, se reporta mayor prevalencia del primero en la cavidad oral de individuos sanos (24), lo cual se debe, en parte, a que solo en las últimas décadas se ha reconocido la posibilidad de infecciones orofaciales por HSV-2.

En el presente estudio no se detectó el HSV-1 y cuatro de los 17 pacientes presentaron descarga de HSV-2 sin signos clínicos, en contradicción con lo registrado en la mayoría de trabajos, en los cuales se ha detectado el HSV-1 en mayor medida $(25,26)$.

La descarga de HSV-2 en la cavidad oral se ha evaluado en el contexto de las enfermedades de transmisión sexual; Wald, et al. (10), evaluaron 1.388 individuos con antecedentes de infección por HSV-2, de los cuales 44 fueron positivos para este virus en la cavidad oral y tres presentaron lesiones en la mucosa. Según estos autores, aunque la probabilidad de detectar descargas positivas en 
la saliva es baja, la inmunosupresión asociada a la infección por HIV puede ser el principal factor de riesgo (10).

Kim, et al. (27), evaluaron hisopados orofaríngeos de 109 hombres seropositivos para HSV-2 y detectaron descarga en 82 de ellos, de los cuales 48 eran positivos para el HIV y 34 eran negativos. La descarga estuvo acompañada de lesiones en la mucosa oral, al igual que en los pacientes de este estudio, con lo cual queda claro que la descarga viral no ocurre en todos los individuos infectados.

Sepúlveda, et al. (9), compararon 30 niños con cáncer y 27 controles sanos en cuanto a la eliminación oral de HSV-1 y 2, y detectaron la de HSV-1 asociada con pancitopenia grave. Solo uno de los controles presentó descarga positiva para HSV-1 y en ningún caso se detectó una de HSV-2. En el presente trabajo, los pacientes 2 y 13 presentaban leucopenia grave en el momento de la detección del HSV-2 en la saliva, y en los pacientes 5 y 11, el recuento de HSV-2 fue levemente bajo y normal, respectivamente. No obstante, en algunos pacientes con recuentos leucocitarios bajos, no se presentó descarga viral de ninguno de los virus evaluados.

La inmunidad celular controla la producción de partículas virales en los ganglios del trigémino $(28,29)$ y es probable que durante la inmunosupresión causada por el acondicionamiento se reactiven los virus, con el consecuente transporte anterógrado de viriones hacia la mucosa oral, los cuales infectan y se replican en las células epiteliales.

La reacción inmunitaria podría ser más efectiva para controlar la replicación del HSV-2 en ganglios del trigémino que en los ganglios nerviosos de la región sacra, con una posible interacción entre los genes virales y el medio celular específico en cada uno de estos ganglios, lo cual explicaría la infrecuencia de la reactivación del HSV-2 por encima del HSV-1 en ganglios del trigémino en individuos inmunocompetentes y su mayor frecuencia en individuos inmunocomprometidos (10).

La administración de aciclovir a todos los pacientes normalmente previene la reactivación del HSV-1 y del 2. Sin embargo, se ha comprobado que la prevalencia de las infecciones por virus del herpes simple es mayor en individuos inmunocomprometidos, principalmente, en los receptores de trasplante de precursores hematopoyéticos, con un rango de 4,1 a 10,9\%. Este aumento parece deberse a la aparición de mutantes resistentes en los pacientes receptores de trasplante (30-32).
La probabilidad de las infecciones por HSV en estos pacientes es mayor. De las 105 muestras analizadas en este estudio, en diez tomadas de cuatro pacientes se detectó descarga de HSV-2, lo cual es una proporción baja (9,5\%). El paciente 2 resultó seronegativo para HSV-1 y 2 al ingresar a la unidad de trasplante y, en la semana 4, así como a partir de la semana 6 , siempre resultó positivo para HSV-2 en las muestras de saliva.

Se concluyó que, incluso con la administración de aciclovir desde el inicio del acondicionamiento, fue posible detectar la reactivación del HSV-2 en los receptores de trasplante de precursores hematopoyéticos. Es posible que este grupo de pacientes no estuviera previamente infectado con HSV-1, ni hubiera tenido contacto con el virus durante el tratamiento y, por lo tanto, no presentara la reactivación. Es posible que, a pesar de la inmunosupresión, la reacción inmunitaria impidiera la reactivación o que esta se debiera a la profilaxis antiviral. En el contexto de este trabajo, no fue posible corroborar ninguna de estas hipótesis.

La técnica de PCR anidada empleada en este estudio para detectar el ADN del HSV-1 y 2 se ajustó al protocolo de Sun, et al. (21), quienes obtuvieron hisopados de mucosa oral, de piel y de la zona genital. La técnica ha demostrado ser efectiva para detectar el ADN del HSV-1 en ganglios del trigémino obtenidos de cadáveres (33), por lo cual la ausencia del ADN del HSV-1 no parece deberse a una dificultad técnica.

La infección o reactivación del CMV en los pacientes con trasplante es una de las principales causas de complicaciones, y el riesgo es mayor en los casos de un donante positivo y un receptor negativo (34). Los pacientes 3 y 5 , que presentaron descargas positivas para CMV en la saliva, recibieron trasplante de donantes IgG positivos, y en la semana 12 la PCR para CMV en el paciente 5 fue positiva en células mononucleares de sangre periférica, aunque en él se había detectado descarga en la saliva desde el momento de la hospitalización.

Se sabe que existe relación entre la inmunosupresión y la reactivación de CMV y EBV $(35,36)$, y en pacientes positivos para HIV-1 se ha corroborado, además, que la descarga en saliva de CMV ocurre independientemente de la detección en sangre o en orina (37).

El CMV permanece latente en células CD34+ y en monocitos CD14+; desde allí puede llegar a distintos órganos y tejidos, como las glándulas 
salivares (38), infectar otras células y mantener una producción viral continua, lo cual apunta a que la saliva es la muestra idónea para detectar la reactivación viral (17).

Griffin, et al., evaluaron la relación de las eliminaciones de HSV-1, HSV-2, CMV y EBV en la saliva de pacientes positivos para el HIV-1, y encontraron que en individuos con descargas de EBV era más probable encontrar el ADN de CMV, sobre todo en los días en que se detectaban descargas de HSV o EBV. Los autores concluyeron que habría factores independientes entre sí que influyen en la presencia de la descarga de los tres tipos de virus del herpes en la cavidad oral, pero que también pueden existir interacciones entre estos virus (39).

Los cuatro pacientes de este estudio con eliminaciones de CMV también presentaron EBV, lo cual respalda la hipótesis de que hay mayor probabilidad de detectar descargas de CMV en los días en que también se detecta el EBV (39).

Se observó que la descarga de CMV en la saliva es independiente de la reactivación de la infección en células mononucleares de sangre periférica, como se ha concluido en otros estudios (39). Se debe considerar que la aplasia disminuye la posibilidad de recuperar el ADN de células en sangre periférica, lo cual dificulta el diagnóstico. En el presente trabajo todos los pacientes con resultados positivos en saliva, también tuvieron resultado positivo de antigenemia o en la PCR en sangre periférica, por lo que se puede pensar que no se produjeron falsos positivos en las muestras.

En cuanto a la relación de la descarga de CMV con el recuento leucocitario, es evidente que cuando las muestras eran positivas, los pacientes presentaban leucopenia; es de resaltar, además, que los cuatro pacientes positivos para este virus habían recibido trasplante alogénico de cordón umbilical.

La relación entre la descarga de EBV en saliva y la leucopenia no es tan clara, ya que algunos pacientes presentaron recuentos normales a pesar de haberse detectado la descarga. El paciente 5 tenía diagnóstico de síndrome linfoproliferativo postrasplante asociado con el EBV y en él se detectaron descargas de este virus desde la primera semana.

En este trabajo se detectaron descargas de HSV-2, CMV y EBV en la saliva de pacientes pediátricos receptores de trasplante de precursores hematopoyéticos asociadas a recuentos leucocitarios bajos y trasplante alogénico. En los pacientes evaluados se observó que la descarga de virus del herpes en la saliva no fue constante 0 permanente y que su comportamiento es diferente en sangre periférica.

También, se pudo corroborar que la saliva puede emplearse como un medio seguro y de fácil obtención para evaluar las descargas virales asintomáticas.

\section{Agradecimientos}

Al Laboratorio de Biología Molecular de la Clínica Colombia de Colsanitas, por facilitar el control positivo para CMV, y a los pacientes, acudientes y personal médico y paramédico de la Unidad de Trasplante de Precursores Hematopoyéticos de la Fundación HOMI - Hospital de la Misericordia.

\section{Conflicto de intereses}

Los autores declaran no tener conflicto de intereses.

\section{Financiación}

Este proyecto fue financiado por la Dirección de Investigación de la Universidad Nacional de Colombia, sede Bogotá, y la Vicerrectoría de Investigaciones de la Universidad El Bosque.

\section{Referencias}

1. Whitley RJ, Roizman B. Herpes simplex virus infections. Lancet. 2001;357:1513-8. http://dx.doi.org/10.1016/S01406736(00)04638-9

2. Doumas S, Vladikas A, Papagianni M. Kolokotronis A. Human cytomegalovirus-associated oral and maxillo-facial disease. Clin Microbiol Infect. 2007;13:557-9. http://dx.doi. org/10.1111/j.1469-0691.2007.01714.x

3. Davison AJ. Herpesvirus systematics. Vet Microbiol. 2010; 143:52-69. http://dx.doi.org/10.1016/j.vetmic.2010.02.014

4. Wald A, Corey L. Persistence in the population: Epidemiology and transmission. En: Arvin A, CampadelliFiume G, Mocarski E, Moore PS, Roizman B, Whitley R, et al., editors. Human herpesviruses: Biology, therapy and immunoprophylaxis. Cambridge: Cambridge University Press;2007. p. 1-31.

5. Wilson AC, Mohr I. A cultured affair: HSV latency and reactivation in neurons. Trends Microbiol. 2012;20:604-11. http://dx.doi.org/10.1016/j.tim.2012.08.005

6. Sinclair JH, Reeves MB. Human cytomegalovirus manipulation of latently infected cells. Viruses. 2013;5:2803-24. http://dx.doi.org/doi:10.3390/v5112803

7. Tsurumi T, Fujita M, Kudoh A. Latent and lytic EpsteinBarr virus replication strategies. Rev Med Virol. 2005;15:315. http://dx.doi.org/10.1002/rmv.441

8. Sacks SL, Griffiths PD, Corey L, Cohen C, Cunningham A, Dusheiko GM, et al. HSV shedding. Antiviral Res. 2004;63(Supl.1):S19-26. http://dx.doi.org/10.1016/j.antiviral. 2004.06.004 
9. Sepúlveda E, Rojas IG, Brethauer U, Maulén NP, Muñoz M, Kirsten L, et al. Effect of white cell counts on the presence of human herpes simplex virus type-1 in saliva of pediatric oncology patients. Oral Surg Oral Med Oral Pathol Oral Radiol Endod. 2008;105:583-8. http://dx.doi. org/10.1016/j.tripleo.2007.12.035

10. Wald A, Eriksson M, Krantz E, Selke S, Corey L. Oral shedding of herpes simplex virus type 2 . Sex Transm Infect. 2004;80:272-6. http://dx.doi.org/10.1136/sti.2003.007823

11. Morfin F, Bilger K, Boucher A, Thiebaut A, Najioullah $\mathbf{F}$, Bleyzac $\mathbf{N}$, et al. HSV excretion after bone marrow transplantation: A 4-year survey. J Clin Virol. 2004;30:341-5. http://dx.doi.org/10.1016/j.jcv.2004.03.002

12. Cannon MJ, Hyde TB, Schmid DS. Review of cytomegalovirus shedding in bodily fluids and relevance to congenital cytomegalovirus infection. Rev Med Virol. 2011;21:240-55. http://dx.doi.org/10.1002/rmv.695

13. Jaskula E, Dlubek D, Sedzimirska M, Duda D, Tarnowska A, Lange A. Reactivations of cytomegalovirus, human herpes virus 6, and Epstein-Barr virus differ with respect to risk factors and clinical outcome after hematopoietic stem cell transplantation. Transplant Proc. 2010;42:3273-6. http:// dx.doi.org/10.1016/j.transproceed.2010.07.027

14. Hug M, Dorner M, Fröhlich FZ, Gysin C, Neuhaus D, Nadal D. Pediatric Epstein-Barr virus carriers with or without tonsillar enlargement may substantially contribute to spreading of the virus. J Infect Dis. 2010;202:1192-9. http://dx.doi.org/10.1086/656335

15. Lucht E, Biberfeld P, Linde A. Epstein-Barr virus (EBV) DNA in saliva and EBV serology of HIV-1-infected persons with and without hairy leukoplakia. J Infect. 1995;31:189-94.

16. Cordonnier C. Infections after HSCT. In: Apperley J, Carreras E, Gluckman E, Gratwohl A, Masszi T, editors. ESH-EBMT Handbook. Haematopoietic Stem Cell Transplantation. 5th edition. Paris: European School of Haematology; 2008. p. 198-217.

17. Correia-Silva JdeF, Victória JM, Guimarães AL, Salomão $\mathrm{UE}$, de Abreu MH, Bittencourt $\mathrm{H}$, et al. Cytomegalovirus shedding in the oral cavity of allogeneic haematopoietic stem cell transplant patients. Oral Dis. 2007;13:163-9. http:// dx.doi.org/10.1111/j.1601-0825.2006.01240.x

18. Preiksaitis JK, Díaz-Mitoma F, Mirzayans F, Roberts S, Tyrrell DL. Quantitative oropharyngeal Epstein-Barr virus shedding in renal and cardiac transplant recipients: Relationship to immunosuppressive therapy, serologic responses, and the risk of post-transplant lymphoproliferative disorder. J Infect Dis.1992;166:986-94. http://dx.doi.org/10.1093/ infdis/166.5.986

19. Perera RA, Samaranayake LP, Tsang CS. Shedding dynamics of Epstein-Barr virus: A type 1 carcinogen. Arch Oral Biol. 2010;55:639-47. http://dx.doi.org/10.1016/j. archoralbio.2010.06.009

20. Kessler HH, Pierer K, Weber B, Sakrauski A. Detection of herpes simplex virus DNA from cerebrospinal fluid by PCR and a rapid, nonradioactive hybridization technique. J Clin Microbiol. 1994;32:1881-6.

21. Sun Y, Kum R, Hoon S, Pei P. Detection and genotyping of human herpes simplex viruses in cutaneous lesions of erythema multiforme by nested PCR. J Med Virol. 2003;71: 423-8. http://dx.doi.org/10.1002/jmv.10502

22. Shin CH, Park GS, Hong KM, Paik MK. Detection and typing of HSV-1, HSV-2, CMV and EBV by quadruplex PCR. Yonsei Med J. 2003;44:1001-7. http://dx.doi.org/10.3349/ ymj.2003.44.6.1001

23. Sahin F, Gerceker D, Karasartova D, Ozsan TM. Detection of herpes simplex virus type 1 in addition to Epstein-Bar virus in tonsils using a new multiplex polymerase chain reaction assay. Diagn Microbiol Infect Dis. 2007;57:47-51. http://dx. doi.org/10.1016/j.diagmicrobio.2006.09.013

24. Miller CS, Danaher RJ. Asymptomatic shedding of herpes simplex virus (HSV) in the oral cavity. Oral Surg Oral Med Oral Pathol Oral Radiol Endod. 2008;105:43-50. http:// dx.doi.org/10.1016/j.tripleo.2007.06.011

25. Hyland PL, Coulter WA, Ruman A, Fulton CR, O'Neill HJ, Coyle PV, et al. Asymptomatic shedding of HSV-1 in patients undergoing oral surgical procedures and attending for noninvasive treatment. Oral Dis. 2007;13:414-8. http:// dx.doi.org/10.1111/j.1601-0825.2007.01316.x

26. Scott DA, Coulter WA, Lamey PJ. Oral shedding of herpes simplex virus tipe 1: A review. J Oral Pathol Med. 1997;26:441-7. http://dx.doi.org/10.1111/j.1600-0714.1997. tb00012.x

27. Kim HN, Meier A, Huang ML, Kuntz S, Selke S, Celum C, et al. Oral herpes simplex virus type 2 reactivation in HIV-positive and HIV-negative men. J Infect Dis. 2006;194: 420-7. http://dx.doi.org/10.1086/505879

28. Christensen J, Thomsen A. Coordinating innate and adaptive immunity to viral infection: Mobility is the key. APMIS. 2009;117:338-55. http://dx.doi.org/10.1111/j.16000463.2009.02451.x

29. Bonjardim A. Interferons (IFNs) are key cytokines in both innate and adaptive antiviral immune responses and viruses counteract IFN action. Microbes Infect. 2005;7:56978. http://dx.doi.org/10.1016/j.micinf.2005.02.001

30. Piret J, Boivin G. Resistance of herpes simplex viruses to nucleoside analogues: Mechanisms, prevalence, and management. Antimicrob Agents Chemother. 2011;55:45972. http://dx.doi.org/10.1128/ACC.00615-10

31. Chakrabarti S, Pillay D, Ratcliffe D, Cane PA, Collingham $\mathrm{KE}$, Milligan DW. Resistance to antiviral drugs in herpes simplex virus infections among allogeneic stem cell transplant recipients: Risk factors and prognostic significance. J Infect Dis. 2000;181:2055-8. http://dx.doi.org/10.1086/315524

32. Danve-Szatanek C, Aymard M, Thouvenot D, Morfin F, Agius G, Bertin I, et al. Surveillance network for herpes simplex virus resistance to antiviral drugs: 3-year follow-up. J Clin Microbiol. 2004;42:242-9. http://dx.doi.org/10.1128/ JCM.42.1.242-249.2004.

33. Bernal LJ, Ávila LV, Marín LM, Casas JA, Bohórquez SP, Barrientos S, et al. Detección de la presencia de antígeno y ADN de virus herpes simplex tipo 1 en ganglios trigeminales humanos. Univ Odontol. 2012;31:117-24.

34. Manuel O, Panq XL, Humar A, Humar D, Doucette K, Preiksaitis JK. An assessment of donor-to-recipient transmission patterns of human cytomegalovirus by analysis of viral genomic variants. J Infect Dis. 2009;199:1621-8. http://dx.doi.org/10.1086/598952 
35. Chêne A, Nylén S, Donati D, Bejarano MT, Kironde F, Wahlgren M, et al. Effect of acute Plasmodium falciparum malaria on reactivation and shedding of the eight human herpes viruses. PLoS ONE. 2011;6:e26266. http://dx.doi. org/10.1371/journal.pone.0026266

36. Lucht E, Brytting M, Bjerregaard L, Julander I, Linde A. Shedding of cytomegalovirus and herpesviruses 6,7 , and 8 in saliva of human immunodeficiency virus type 1-infected patients and healthy controls. Clin Infect Dis. 1998;27:13741. http://dx.doi.org/10.1086/514604

37. Greenberg MS, Dubin G, Stewart JC, Cumming CG, MacGregor RR, Friedman HM. Relationship of oral disease to the presence of cytomegalovirus DNA in the saliva of AIDS patients. Oral Surg Oral Med Oral Pathol Oral Radiol Endod. 1995;79:175-9. http://dx.doi.org/10.1016/ S1079-2104(05)80278-1

38. Sinclair J, Reeves M. The intimate relationship between human cytomegalovirus and the dendritic cell lineage. Front Microbiol. 2014;7:1-14. http://dx.doi.org/10.3389/ fmicb.2014.00389

39. Griffin E, Krantz E, Selke S, Huang ML, Wald A. Oral mucosal reactivation rates of herpes viruses among HIV-1 seropositive persons. J Med Virol. 2008;80:1153-9. http:// dx.doi.org/10.1002/jmv.21214 